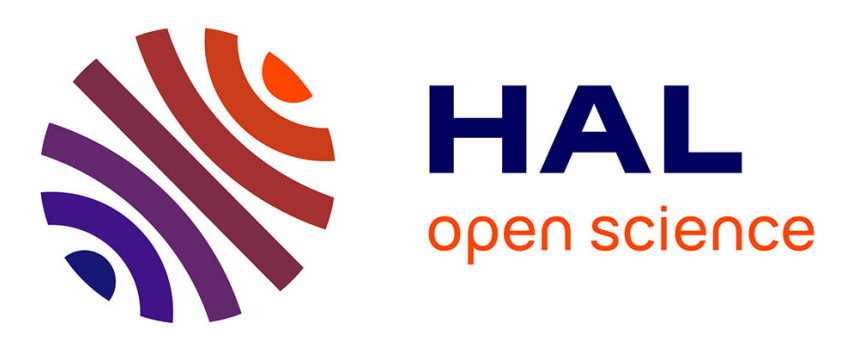

\title{
An Omnidirectional Stereoscopic System for Mobile Robot Navigation
}

Rémi Boutteau, Xavier Savatier, Jean-Yves Ertaud, Belahcene Mazari

\section{To cite this version:}

Rémi Boutteau, Xavier Savatier, Jean-Yves Ertaud, Belahcene Mazari. An Omnidirectional Stereoscopic System for Mobile Robot Navigation. Sensors \& Transducers Journal, 2009. hal-01710395

\section{HAL Id: hal-01710395 \\ https://hal.science/hal-01710395}

Submitted on 15 Feb 2018

HAL is a multi-disciplinary open access archive for the deposit and dissemination of scientific research documents, whether they are published or not. The documents may come from teaching and research institutions in France or abroad, or from public or private research centers.
L'archive ouverte pluridisciplinaire HAL, est destinée au dépôt et à la diffusion de documents scientifiques de niveau recherche, publiés ou non, émanant des établissements d'enseignement et de recherche français ou étrangers, des laboratoires publics ou privés. 
ISSN 1726-5749
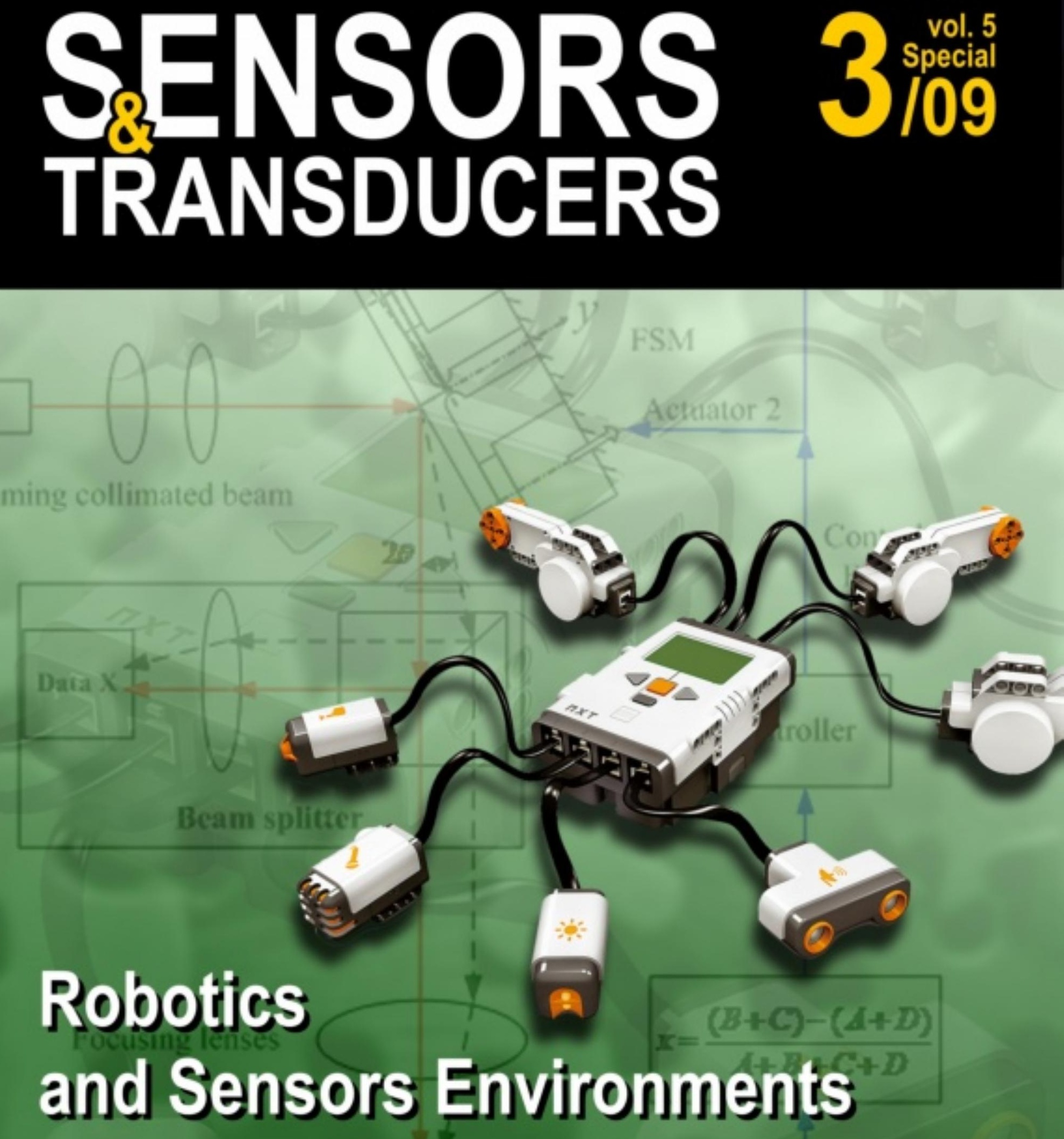

International Frequency Sensor Association Publishing

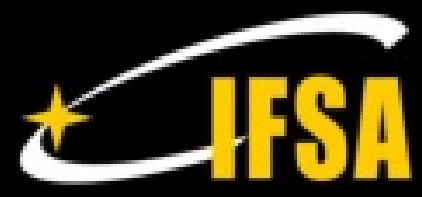




\title{
CIrsh \\ Sensors \& Transducers
}

Volume 4, Special Issue

March 2009

\author{
www.sensorsportal.com
}

ISSN 1726-5479

Guest Editors: Dr. Pierre Payeur and Dr. Emil M. Petriu, University of Ottawa, Ottawa, ON, Canada

Editor-in-Chief: professor Sergey Y. Yurish, phone: +34 696067716, fax: +34 93 4011989, e-mail: editor@sensorsportal.com

\section{Editors for Western Europe}

Meijer, Gerard C.M., Delft University of Technology, The Netherlands

Ferrari, Vittorio, Universitá di Brescia, Italy

Editor South America

Costa-Felix, Rodrigo, Inmetro, Brazil

Editor for Eastern Europe

Sachenko, Anatoly, Ternopil State Economic University, Ukraine

\author{
Editors for North America \\ Datskos, Panos G., Oak Ridge National Laboratory, USA \\ Fabien, J. Josse, Marquette University, USA \\ Katz, Evgeny, Clarkson University, USA \\ Editor for Asia \\ Ohyama, Shinji, Tokyo Institute of Technology, Japan \\ Editor for Asia-Pacific \\ Mukhopadhyay, Subhas, Massey University, New Zealand
}

\section{Editorial Advisory Board}

Abdul Rahim, Ruzairi, Universiti Teknologi, Malaysia

Ahmad, Mohd Noor, Nothern University of Engineering, Malaysia

Annamalai, Karthigeyan, National Institute of Advanced Industrial Science and Technology, Japan

Arcega, Francisco, University of Zaragoza, Spain

Arguel, Philippe, CNRS, France

Ahn, Jae-Pyoung, Korea Institute of Science and Technology, Korea

Arndt, Michael, Robert Bosch GmbH, Germany

Ascoli, Giorgio, George Mason University, USA

Atalay, Selcuk, Inonu University, Turkey

Atghiaee, Ahmad, University of Tehran, Iran

Augutis, Vygantas, Kaunas University of Technology, Lithuania

Avachit, Patil Lalchand, North Maharashtra University, India

Ayesh, Aladdin, De Montfort University, UK

Bahreyni, Behraad, University of Manitoba, Canada

Baoxian, Ye, Zhengzhou University, China

Barford, Lee, Agilent Laboratories, USA

Barlingay, Ravindra, RF Arrays Systems, India

Basu, Sukumar, Jadavpur University, India

Beck, Stephen, University of Sheffield, UK

Ben Bouzid, Sihem, Institut National de Recherche Scientifique, Tunisia

Benachaiba, Chellali, Universitaire de Bechar, Algeria

Binnie, T. David, Napier University, UK

Bischoff, Gerlinde, Inst. Analytical Chemistry, Germany

Bodas, Dhananjay, IMTEK, Germany

Borges Carval, Nuno, Universidade de Aveiro, Portugal

Bousbia-Salah, Mounir, University of Annaba, Algeria

Bouvet, Marcel, CNRS - UPMC, France

Brudzewski, Kazimierz, Warsaw University of Technology, Poland

Cai, Chenxin, Nanjing Normal University, China

Cai, Qingyun, Hunan University, China

Campanella, Luigi, University La Sapienza, Italy

Carvalho, Vitor, Minho University, Portugal

Cecelja, Franjo, Brunel University, London, UK

Cerda Belmonte, Judith, Imperial College London, UK

Chakrabarty, Chandan Kumar, Universiti Tenaga Nasional, Malaysia

Chakravorty, Dipankar, Association for the Cultivation of Science, India

Changhai, Ru, Harbin Engineering University, China

Chaudhari, Gajanan, Shri Shivaji Science College, India

Chen, Jiming, Zhejiang University, China

Chen, Rongshun, National Tsing Hua University, Taiwan

Cheng, Kuo-Sheng, National Cheng Kung University, Taiwan

Chiang, Jeffrey (Cheng-Ta), Industrial Technol. Research Institute, Taiwan

Chiriac, Horia, National Institute of Research and Development, Romania

Chowdhuri, Arijit, University of Delhi, India

Chung, Wen-Yaw, Chung Yuan Christian University, Taiwan

Corres, Jesus, Universidad Publica de Navarra, Spain

Cortes, Camilo A., Universidad Nacional de Colombia, Colombia

Courtois, Christian, Universite de Valenciennes, France

Cusano, Andrea, University of Sannio, Italy

D'Amico, Arnaldo, Università di Tor Vergata, Italy

De Stefano, Luca, Institute for Microelectronics and Microsystem, Italy

Deshmukh, Kiran, Shri Shivaji Mahavidyalaya, Barshi, India

Dickert, Franz L., Vienna University, Austria

Dieguez, Angel, University of Barcelona, Spain

Dimitropoulos, Panos, University of Thessaly, Greece

Ding Jian, Ning, Jiangsu University, China

Djordjevich, Alexandar, City University of Hong Kong, Hong Kong
Donato, Nicola, University of Messina, Italy

Donato, Patricio, Universidad de Mar del Plata, Argentina

Dong, Feng, Tianjin University, China

Drljaca, Predrag, Instersema Sensoric SA, Switzerland

Dubey, Venketesh, Bournemouth University, UK

Enderle, Stefan, University of Ulm and KTB Mechatronics GmbH,

Germany

Erdem, Gursan K. Arzum, Ege University, Turkey

Erkmen, Aydan M., Middle East Technical University, Turkey

Estelle, Patrice, Insa Rennes, France

Estrada, Horacio, University of North Carolina, USA

Faiz, Adil, INSA Lyon, France

Fericean, Sorin, Balluff GmbH, Germany

Fernandes, Joana M., University of Porto, Portugal

Francioso, Luca, CNR-IMM Institute for Microelectronics and

Microsystems, Italy

Francis, Laurent, University Catholique de Louvain, Belgium

Fu, Weiling, South-Western Hospital, Chongqing, China

Gaura, Elena, Coventry University, UK

Geng, Yanfeng, China University of Petroleum, China

Gole, James, Georgia Institute of Technology, USA

Gong, Hao, National University of Singapore, Singapore

Gonzalez de la Rosa, Juan Jose, University of Cadiz, Spain

Granel, Annette, Goteborg University, Sweden

Graff, Mason, The University of Texas at Arlington, USA

Guan, Shan, Eastman Kodak, USA

Guillet, Bruno, University of Caen, France

Guo, Zhen, New Jersey Institute of Technology, USA

Gupta, Narendra Kumar, Napier University, UK

Hadjiloucas, Sillas, The University of Reading, UK

Hashsham, Syed, Michigan State University, USA

Hernandez, Alvaro, University of Alcala, Spain

Hernandez, Wilmar, Universidad Politecnica de Madrid, Spain

Homentcovschi, Dorel, SUNY Binghamton, USA

Horstman, Tom, U.S. Automation Group, LLC, USA

Hsiai, Tzung (John), University of Southern California, USA

Huang, Jeng-Sheng, Chung Yuan Christian University, Taiwan

Huang, Star, National Tsing Hua University, Taiwan

Huang, Wei, PSG Design Center, USA

Hui, David, University of New Orleans, USA

Jaffrezic-Renault, Nicole, Ecole Centrale de Lyon, France

Jaime Calvo-Galleg, Jaime, Universidad de Salamanca, Spain

James, Daniel, Griffith University, Australia

Janting, Jakob, DELTA Danish Electronics, Denmark

Jiang, Liudi, University of Southampton, UK

Jiang, Wei, University of Virginia, USA

Jiao, Zheng, Shanghai University, China

John, Joachim, IMEC, Belgium

Kalach, Andrew, Voronezh Institute of Ministry of Interior, Russia

Kang, Moonho, Sunmoon University, Korea South

Kaniusas, Eugenijus, Vienna University of Technology, Austria

Katake, Anup, Texas A\&M University, USA

Kausel, Wilfried, University of Music, Vienna, Austria

Kavasoglu, Nese, Mugla University, Turkey

Ke, Cathy, Tyndall National Institute, Ireland

Khan, Asif, Aligarh Muslim University, Aligarh, India

Kim, Min Young, Kyungpook National University, Korea South

Sandacci, Serghei, Sensor Technology Ltd., UK 
Ko, Sang Choon, Electronics and Telecommunications Research Institute, Korea South

Kockar, Hakan, Balikesir University, Turkey

Kotulska, Malgorzata, Wroclaw University of Technology, Poland

Kratz, Henrik, Uppsala University, Sweden

Kumar, Arun, University of South Florida, USA

Kumar, Subodh, National Physical Laboratory, India

Kung, Chih-Hsien, Chang-Jung Christian University, Taiwan

Lacnjevac, Caslav, University of Belgrade, Serbia

Lay-Ekuakille, Aime, University of Lecce, Italy

Lee, Jang Myung, Pusan National University, Korea South

Lee, Jun Su, Amkor Technology, Inc. South Korea

Lei, Hua, National Starch and Chemical Company, USA

Li, Genxi, Nanjing University, China

Li, Hui, Shanghai Jiaotong University, China

Li, Xian-Fang, Central South University, China

Liang, Yuanchang, University of Washington, USA

Liawruangrath, Saisunee, Chiang Mai University, Thailand

Liew, Kim Meow, City University of Hong Kong, Hong Kong

Lin, Hermann, National Kaohsiung University, Taiwan

Lin, Paul, Cleveland State University, USA

Linderholm, Pontus, EPFL - Microsystems Laboratory, Switzerland

Liu, Aihua, University of Oklahoma, USA

Liu Changgeng, Louisiana State University, USA

Liu, Cheng-Hsien, National Tsing Hua University, Taiwan

Liu, Songqin, Southeast University, China

Lodeiro, Carlos, Universidade NOVA de Lisboa, Portugal

Lorenzo, Maria Encarnacio, Universidad Autonoma de Madrid, Spain

Lukaszewicz, Jerzy Pawel, Nicholas Copernicus University, Poland

Ma, Zhanfang, Northeast Normal University, China

Majstorovic, Vidosav, University of Belgrade, Serbia

Marquez, Alfredo, Centro de Investigacion en Materiales Avanzados,

Mexico

Matay, Ladislav, Slovak Academy of Sciences, Slovakia

Mathur, Prafull, National Physical Laboratory, India

Maurya, D.K., Institute of Materials Research and Engineering, Singapore

Mekid, Samir, University of Manchester, UK

Melnyk, Ivan, Photon Control Inc., Canada

Mendes, Paulo, University of Minho, Portugal

Mennell, Julie, Northumbria University, UK

Mi, Bin, Boston Scientific Corporation, USA

Minas, Graca, University of Minho, Portugal

Moghavvemi, Mahmoud, University of Malaya, Malaysia

Mohammadi, Mohammad-Reza, University of Cambridge, UK

Molina Flores, Esteban, Benemérita Universidad Autónoma de Puebla,

Mexico

Moradi, Majid, University of Kerman, Iran

Morello, Rosario, DIMET, University "Mediterranea" of Reggio Calabria, Italy

Mounir, Ben Ali, University of Sousse, Tunisia

Mulla, Imtiaz Sirajuddin, National Chemical Laboratory, Pune, India

Neelamegam, Periasamy, Sastra Deemed University, India

Neshkova, Milka, Bulgarian Academy of Sciences, Bulgaria

Oberhammer, Joachim, Royal Institute of Technology, Sweden

Ould Lahoucine, Cherif, University of Guelma, Algeria

Pamidighanta, Sayanu, Bharat Electronics Limited (BEL), India

Pan, Jisheng, Institute of Materials Research \& Engineering, Singapore

Park, Joon-Shik, Korea Electronics Technology Institute, Korea South

Penza, Michele, ENEA C.R., Italy

Pereira, Jose Miguel, Instituto Politecnico de Setebal, Portugal

Petsev, Dimiter, University of New Mexico, USA

Pogacnik, Lea, University of Ljubljana, Slovenia

Post, Michael, National Research Council, Canada

Prance, Robert, University of Sussex, UK

Prasad, Ambika, Gulbarga University, India

Prateepasen, Asa, Kingmoungut's University of Technology, Thailand

Pullini, Daniele, Centro Ricerche FIAT, Italy

Pumera, Martin, National Institute for Materials Science, Japan

Radhakrishnan, S. National Chemical Laboratory, Pune, India

Rajanna, K., Indian Institute of Science, India

Ramadan, Qasem, Institute of Microelectronics, Singapore

Rao, Basuthkar, Tata Inst. of Fundamental Research, India

Raoof, Kosai, Joseph Fourier University of Grenoble, France

Reig, Candid, University of Valencia, Spain

Restivo, Maria Teresa, University of Porto, Portugal

Robert, Michel, University Henri Poincare, France

Rezazadeh, Ghader, Urmia University, Iran

Royo, Santiago, Universitat Politecnica de Catalunya, Spain

Rodriguez, Angel, Universidad Politecnica de Cataluna, Spain

Rothberg, Steve, Loughborough University, UK

Sadana, Ajit, University of Mississippi, USA

Sadeghian Marnani, Hamed, TU Delft, The Netherlands

Sensors \& Transducers Journal (ISSN 1726-5479) is a peer review international journal published monthly online by International Frequency Sensor Association (IFSA).

Available in electronic and CD-ROM. Copyright (C) 2009 by International Frequency Sensor Association. All rights reserved.
Sapozhnikova, Ksenia, D.I.Mendeleyev Institute for Metrology, Russia Saxena, Vibha, Bhbha Atomic Research Centre, Mumbai, India

Schneider, John K., Ultra-Scan Corporation, USA

Seif, Selemani, Alabama A \& M University, USA

Seifter, Achim, Los Alamos National Laboratory, USA

Sengupta, Deepak, Advance Bio-Photonics, India

Shankar, B. Baliga, General Monitors Transnational, USA

Shearwood, Christopher, Nanyang Technological University, Singapore

Shmaliy, Yuriy, Kharkiv National University of Radio Electronics,

Ukraine

Silva Girao, Pedro, Technical University of Lisbon, Portugal

Singh, V. R., National Physical Laboratory, India

Smith, Martin, Open University, UK

Soleymanpour, Ahmad, Damghan Basic Science University, Iran

Somani, Prakash R., Centre for Materials for Electronics Technol., India

Srinivas, Talabattula, Indian Institute of Science, Bangalore, India

Srivastava, Arvind K., Northwestern University, USA

Stefan-van Staden, Raluca-Ioana, University of Pretoria, South Africa

Sumriddetchka, Sarun, National Electronics and Computer Technology Center, Thailand

Sun, Chengliang, Polytechnic University, Hong-Kong

Sun, Dongming, Jilin University, China

Sun, Junhua, Beijing University of Aeronautics and Astronautics, China

Sun, Zhiqiang, Central South University, China

Suri, C. Raman, Institute of Microbial Technology, India

Sysoev, Victor, Saratov State Technical University, Russia

Szewczyk, Roman, Industrial Research Institute for Automation and

Measurement, Poland

Tan, Ooi Kiang, Nanyang Technological University, Singapore,

Tang, Dianping, Southwest University, China

Tang, Jaw-Luen, National Chung Cheng University, Taiwan

Teker, Kasif, Frostburg State University, USA

Thumbavanam Pad, Kartik, Carnegie Mellon University, USA

Tian, Gui Yun, University of Newcastle, UK

Tsiantos, Vassilios, Technological Educational Institute of Kaval, Greece

Tsigara, Anna, National Hellenic Research Foundation, Greece

Twomey, Karen, University College Cork, Ireland

Valente, Antonio, University, Vila Real, - U.T.A.D., Portugal

Vaseashta, Ashok, Marshall University, USA

Vazquez, Carmen, Carlos III University in Madrid, Spain

Vieira, Manuela, Instituto Superior de Engenharia de Lisboa, Portugal

Vigna, Benedetto, STMicroelectronics, Italy

Vrba, Radimir, Brno University of Technology, Czech Republic

Wandelt, Barbara, Technical University of Lodz, Poland

Wang, Jiangping, Xi'an Shiyou University, China

Wang, Kedong, Beihang University, China

Wang, Liang, Advanced Micro Devices, USA

Wang, Mi, University of Leeds, UK

Wang, Shinn-Fwu, Ching Yun University, Taiwan

Wang, Wensheng, University of Pennsylvania, USA

Watson, Steven, Center for NanoSpace Technologies Inc., USA

Weiping, Yan, Dalian University of Technology, China

Wells, Stephen, Southern Company Services, USA

Wolkenberg, Andrzej, Institute of Electron Technology, Poland

Woods, R. Clive, Louisiana State University, USA

Wu, DerHo, National Pingtung University of Science and Technology,

Taiwan

Wu, Zhaoyang, Hunan University, China

Xiu Tao, Ge, Chuzhou University, China

Xu, Lisheng, The Chinese University of Hong Kong, Hong Kong

Xu, Tao, University of California, Irvine, USA

Yang, Dongfang, National Research Council, Canada

Yang, Wuqiang, The University of Manchester, UK

Ymeti, Aurel, University of Twente, Netherland

Yong Zhao, Northeastern University, China

Yu, Haihu, Wuhan University of Technology, China

Yuan, Yong, Massey University, New Zealand

Yufera Garcia, Alberto, Seville University, Spain

Zagnoni, Michele, University of Southampton, UK

Zeni, Luigi, Second University of Naples, Italy

Zhong, Haoxiang, Henan Normal University, China

Zhang, Minglong, Shanghai University, China

Zhang, Qintao, University of California at Berkeley, USA

Zhang, Weiping, Shanghai Jiao Tong University, China

Zhang, Wenming, Shanghai Jiao Tong University, China

Zhou, Zhi-Gang, Tsinghua University, China

Zorzano, Luis, Universidad de La Rioja, Spain

Zourob, Mohammed, University of Cambridge, UK
Shin, Kyuho, Samsung Advanced Institute of Technology, Korea

Slomovitz, Daniel, UTE, Uruguay

Wang, Wei-Chih, University of Washington, USA 


\section{Contents}

Volume 5

Special Issue

www.sensorsportal.com

ISSN 1726-5479

March 2009

\section{Research Articles}

\section{Foreword}

Pierre Payeur and Emil Petriu

An Omnidirectional Stereoscopic System for Mobile Robot Navigation

Rémi Boutteau, Xavier Savatier, Jean-Yves Ertaud, Bélahcène Mazari .....

Movement in Collaborative Robotic Environments Based on the Fish Shoal Emergent Patterns

Razvan Cioarga, Mihai V. Micea, Vladimir Cretu, Emil M. Petriu.

A Multiscale Calibration of a Photon Videomicroscope for Visual Servo Control: Application to MEMS Micromanipulation and Microassembly

Brahim Tamadazte, Sounkalo Dembélé and Nadine Piat.

A Study on Dynamic Stiffening of a Rotating Beam with a Tip Mass

Shengjian Bai, Pinhas Ben-Tzvi, Qingkun Zhou, Xinsheng Huang.....

Towards a Model and Specification for Visual Programming of Massively Distributed Embedded Systems

Meng Wang, Varun Subramanian, Alex Doboli, Daniel Curiac, Dan Pescaru and Codruta Istin ......

Feature Space Dimensionality Reduction for Real-Time Vision-Based Food Inspection Mai Moussa CHETIMA and Pierre PAYEUR

Design and Analysis of a Fast Steering Mirror for Precision Laser Beams Steering Qingkun Zhou, Pinhas Ben-Tzvi and Dapeng Fan.

Neural Gas and Growing Neural Gas Networks for Selective 3D Sensing: a Comparative Study

Ana-Maria Cretu, Pierre Payeur and Emil M. Petriu

Authors are encouraged to submit article in MS Word (doc) and Acrobat (pdf) formats by e-mail: editor@sensorsportal.com Please visit journal's webpage with preparation instructions: http://www.sensorsportal.com/HTML/DIGEST/Submition.htm 


\title{
Sensors \& Transducers
}

ISSN 1726-5479

(C) 2009 by IFSA

http://www.sensorsportal.com

\section{An Omnidirectional Stereoscopic System for Mobile Robot Navigation}

\author{
Rémi BOUTTEAU, Xavier SAVATIER, \\ Jean-Yves ERTAUD, Bélahcène MAZARI \\ Research Institute for Embedded Systems (IRSEEM), \\ Technopole du Madrillet - Av. Galilée - BP10024 \\ 76801 Saint Etienne du Rouvray Cedex - France \\ Tel.: +33232915858 \\ E-mail: remi.boutteau@esigelec.fr
}

Received: 30 January 2009 /Accepted: 20 February 2009 /Published: 23 March 2009

\begin{abstract}
This paper proposes a scheme for a 3D metric reconstruction of the environment of a mobile robot. We first introduce the advantages of a catadioptric stereovision sensor for autonomous navigation and how we have designed it with respect to the Single Viewpoint constraint. For applications such as path generation, the robot needs a metric reconstruction of its environment, therefore a calibration of the sensor is required. After the justification of the chosen model, a calibration method to obtain the model parameters and the relative pose of the two catadioptric sensors is presented. Knowledge of all the sensor parameters yields the $3 \mathrm{D}$ metric reconstruction of the environment by triangulation. The entire process has been evaluated using real data. Copyright (C) 2009 IFSA.
\end{abstract}

Keywords: Omnidirectional sensor, Calibration, Stereovision

\section{Introduction}

The interest in autonomous robots has been growing over the past few years in many applications: intervention in hostile environments, preparation of military intervention, mapping, etc. In many cases, the navigation should be done in an unknown environment and can be helped by $3 \mathrm{D}$ reconstruction.

Autonomous navigation requires a large field of view to provide a complete map of the environment. Therefore, interest for omnidirectional vision, which provides a 360-degree field of view, has 
consequently grown up significantly. To obtain a panoramic image, several methods are being explored: rotating cameras [1], multicamera systems and catadioptric sensors [2]. We chose to work on catadioptric sensors (camera/mirror combination) because they provide a panoramic image instantaneously and without moving parts.

To achieve a 3D reconstruction, it is necessary to have two images of the environment from two different viewpoints either by moving a single camera or by using a multicamera system. The second way is more suitable for dynamic environments because stereo-pair images can be obtained instantaneously and the 3D reconstruction can be initialized without any motion.

The main contribution of the paper is the development and the design/implementation of a complete tool chain, from calibration to $3 \mathrm{D}$ reconstruction.

The following section describes our catadioptric stereovision system and how we designed it to respect the Single View-Point constraint. Section 3 is devoted to the choice of the model. In section 4, we describe the calibration tool developed to determine the model parameters, while in section 5 we present the relative pose estimation of the two sensors. In section 6 we explain how to obtain the $3 \mathrm{D}$ coordinates of points and our experimental results are shown in section 7. Finally, in sections 8 and 9, we draw some conclusions and establish future directions for research.

\section{System Overview}

\subsection{Sensor Description}

It is a well-known fact that a 360-degree field of view offers many advantages for navigation such as interesting optical flow properties [3] and more visual features to track. Although it is possible to reconstruct the environment with only one camera, a stereoscopic sensor can produce a 3D reconstruction instantaneously (without displacement) and will give better results in dynamic scenes.

Among all possible configurations of central catadioptric sensors described by [2], we have chosen to combine two hyperbolic mirrors with two cameras as shown in Fig. 1 for the sake of compactness (a parabolic mirror needs a bulky telecentric lens).

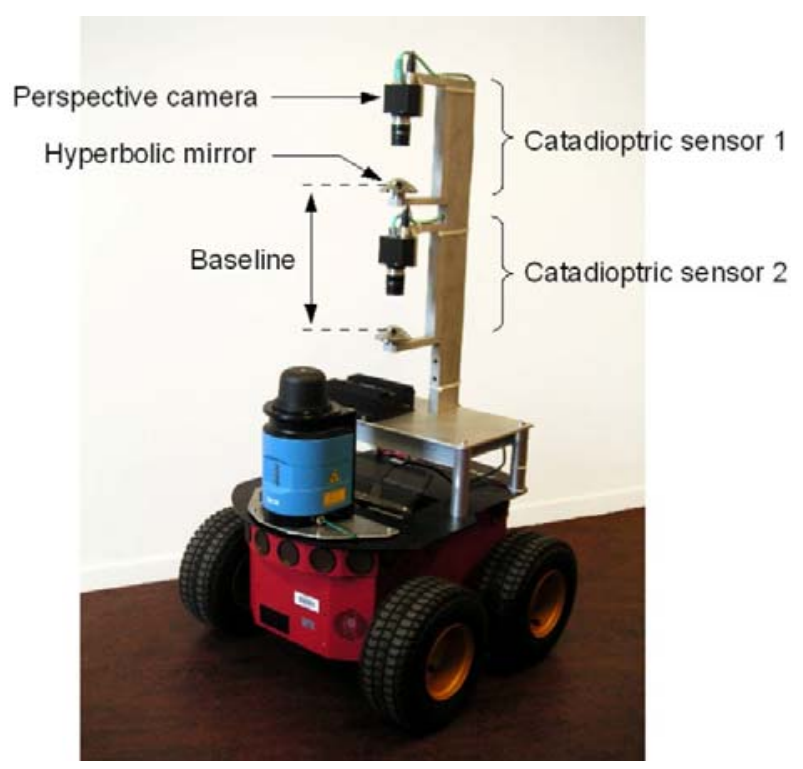

Fig. 1. View of our catadioptric stereovision sensor mounted on a Pioneer robot: The baseline is approximately $20 \mathrm{~cm}$ for indoor environments and can be extended for outdoor environments; the overall height of the sensor is $40 \mathrm{~cm}$. 


\subsection{Imposing the Single-Viewpoint (SVP) Constraint}

The formation of images with catadioptric sensors is based on the Single-Viewpoint (SVP) theory [2]. When the Single-Viewpoint constraint is respected, sensed images are geometrically correct (pure perspective) and the epipolar geometry is applicable. In the case of a hyperbolic mirror, the optical center of the camera has to coincide with the second focus F' of the hyperbola located at a distance of $2 e$ from the mirror focus as illustrated in Fig. 2. The eccentricity $e$ is a parameter of the mirror given by the manufacturer.

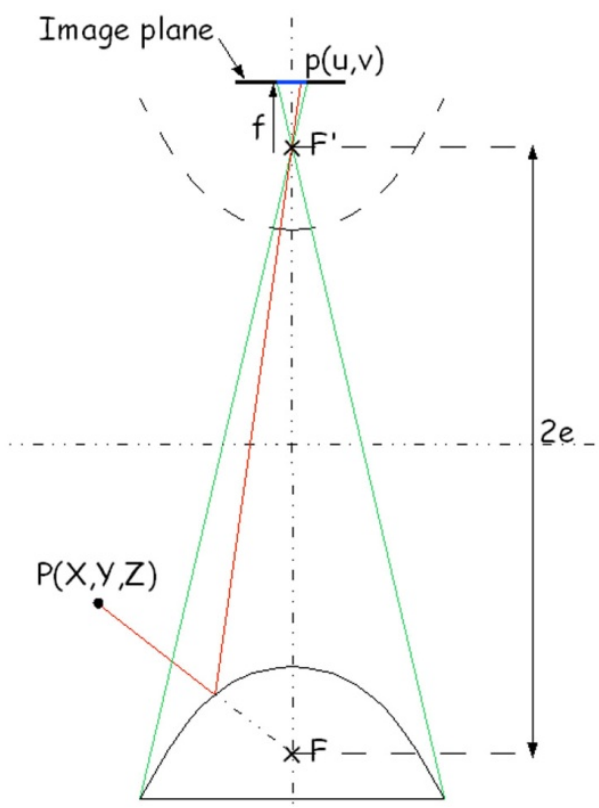

Fig. 2. Image formation with a hyperbolic mirror: the camera center has to be located at $2 \mathrm{e}$ from the mirror focus to respect the SVP constraint.

A key step in designing a catadioptric sensor is to respect this constraint as much as possible. To achieve this, we first calibrate our camera with a standard calibration tool [4] to determine the central point and the focal length. Knowing the parameters of both the mirror and the camera, the image of the mirror on the image plane can be easily predicted if the SVP constraint is respected as illustrated in Fig. 2. The expected mirror boundaries are superposed on the image and the mirror has then to be moved manually to fit this estimation as shown in Fig. 3.

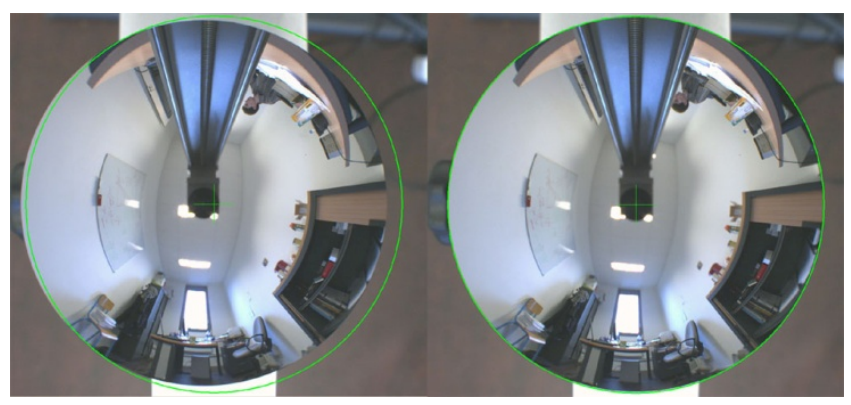

Fig. 3. Adjustment of the mirror position to respect the SVP constraint: the mirror border has to fit the estimation (green circle). 


\section{Projection Model}

The modeling of the sensor is a necessary step before 3D reconstruction can take place because it establishes the relation between the 3D points of the scene and their projections in the image (pixel coordinates). Although there are many calibration methods, they can be classified into two main categories: parametric and non-parametric. The first family consists in finding an appropriate model for the projection of a 3D point onto the image plane. Non-parametric methods associate one projection ray to each pixel [5] [6], and provide a "black box model" of the sensor. They are well adapted for general purposes but they restrict the number of suitable 3D reconstruction algorithms. We consequently chose a parametric calibration method. Using a parametric method requires the choice of the model, which is very important because it has an effect on the complexity and the precision of the calibration process. Several models are available for catadioptric sensors: complete model, polynomial approximation of the projection function and generic model.

The complete model relies on the mirror equation, the camera parameters and the rigid transformation between them to calculate the projection function [7]. The large number of parameters to be estimated leads to an error function which is difficult to minimize because of numerous local minima [8]. The polynomial approximation of the projection function was introduced by Scaramuzza [9], who proposed a calibration toolbox for his model. The generic model, also known as the unified model, was introduced by Geyer [10] and Barreto [11], who proved its validity for all central catadioptric systems. This model was then modified by Mei, who generalized the projection matrix and also took into account the distortions (see [8] for more details). We chose to work with the unified model illustrated in Fig. 4 and described by Mei because any catadioptric system can be used and the number of parameters to be estimated is quite reasonable.

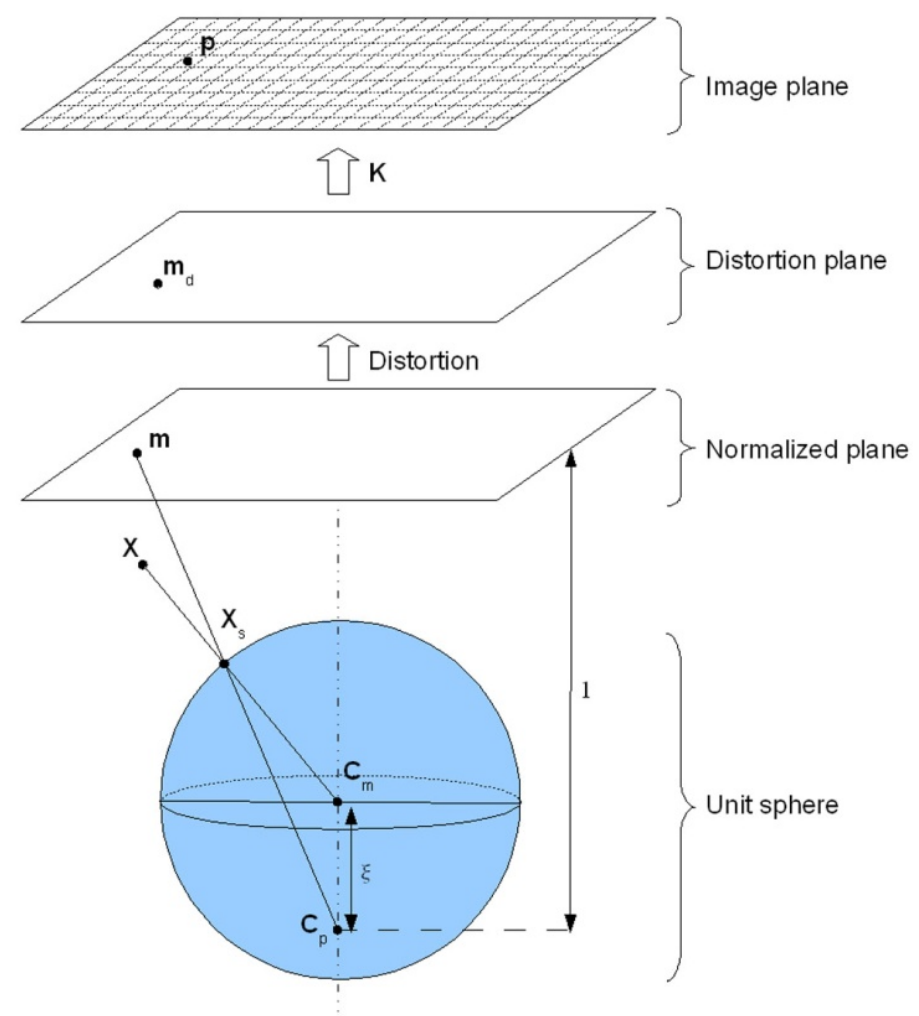

Fig. 4. Unified projection model. 


\subsection{Projection of a 3D point}

A detailed description of the model can be found in [8]. The model contains 11 intrinsic parameters: one mirror parameter $(\xi), 5$ distortion parameters $\left(k_{1}, k_{2}, k_{3}, k_{4}, k_{5}\right)$ and 5 parameters for the generalized camera projection matrix $\left(\alpha, \gamma_{\mathrm{u}}, \gamma_{\mathrm{v}}, u_{0}, v_{0}\right)$. As shown in Fig. 4 , the projection $\mathbf{p}$ of a $3 \mathrm{D}$ point $\mathbf{X}$ can be computed using the following steps:

- The world point $\mathbf{X}$ in the mirror frame is projected onto the unit sphere: $\mathbf{X} \rightarrow \mathbf{X}_{\mathbf{S}}$

- This point is then changed to a new reference frame centered in $\mathbf{C}_{\mathbf{p}}$

- It is then projected onto the normalized plane: $\mathbf{X}_{\mathbf{S}} \rightarrow \mathbf{m}$

- Distortions are added: $\mathbf{m} \rightarrow \mathbf{m}_{\mathbf{d}}$

- A perspective projection is then applied:

$$
\mathbf{p}=\mathbf{K} \cdot \mathbf{m}_{\mathbf{d}}=\left[\begin{array}{ccc}
\gamma_{u} & \gamma_{u} \alpha & u_{0} \\
0 & \gamma_{v} & v_{0} \\
0 & 0 & 1
\end{array}\right] \cdot \mathbf{m}_{\mathbf{d}}
$$

\subsection{Lifting}

The lifting step is the calculation of the point $\mathbf{X}_{\mathrm{S}}$ on the unit sphere corresponding to a pixel, which is very useful for triangulation. Given $\mathbf{m}=\left[\begin{array}{lll}x & y & 1\end{array}\right]^{T}$ the coordinates of the pixel on the normalized plane, we have:

$$
\mathbf{X}_{\mathrm{S}}=\left[\begin{array}{c}
\frac{\xi+\sqrt{1+\left(1-\xi^{2}\right)\left(x^{2}+y^{2}\right)}}{x^{2}+y^{2}+1} x \\
\frac{\xi+\sqrt{1+\left(1-\xi^{2}\right)\left(x^{2}+y^{2}\right)}}{x^{2}+y^{2}+1} y \\
\frac{\xi+\sqrt{1+\left(1-\xi^{2}\right)\left(x^{2}+y^{2}\right)}}{x^{2}+y^{2}+1}-\xi
\end{array}\right]
$$

\section{Calibration}

The calibration step is very easy to achieve because it only requires the catadioptric sensor to observe a planar pattern at different positions. The pattern can be freely moved (the motion does not need to be known) and the user only needs to select the four corners of the pattern. The calibration process is similar to that of Mei [8]. It consists of a minimization over all the model parameters of an error function between the estimated projection of the pattern corners and the measured projection using the Levenberg-Marquardt algorithm.

If $m$ is the number of $3 \mathrm{D}$ points $\mathbf{X}_{\mathbf{i}}, \mathbf{x}_{\mathbf{i}}$ their projections in the images, and $P$ the projection function, we are looking for the parameter vector $\mathbf{v}$ which minimizes the cost function:

$$
F(\mathbf{v})=\frac{1}{2} \sum_{i=1}^{m}\left[P\left(\mathbf{v}, \mathbf{X}_{\mathbf{i}}\right)-\mathbf{x}_{\mathbf{i}}\right]^{2}
$$




\section{Relative Pose Estimation}

Once the sensor calibration is achieved, we have to know the relative pose of the two sensors to process a 3D reconstruction by triangulation. There are two ways to determine the relative pose of the two sensors: either by finding the essential matrix using the epipolar geometry then decomposing it to obtain the translation and the rotation between the two sensors, or by using a pattern to find the relative pose directly. Both methods have been implemented.

\subsection{Essential Matrix Estimation Using Epipolar Geometry}

Epipolar geometry describes the relationship between two cameras. Since it depends only on the parameters of the cameras and their relative pose (it is independent of the scene structure), it can be computed from the correspondence of a few points. The main aim of determining the epipolar geometry is to compute the relative pose of the two sensors (or the displacement of one sensor) but it is also useful for simplifying the search for corresponding points in the two images.

Epipolar geometry is well-known for classical cameras [12] [13]. Given a point on the first image, a line on which the corresponding point lies on the second image can be determined. This line is known as an epipolar line and corresponds to the intersection of an epipolar plane with the image plane. Epipolar geometry of catadioptric sensors is more complicated because of the complex shape of the mirror. It is nevertheless possible to argue from analogy with a classical camera by working with points on the unit sphere (lifted points) rather than image points.

Let the projection of a 3D point $\mathbf{X}$ onto the unit spheres be denoted $\mathbf{X}_{\mathbf{S 1}}$ and $\mathbf{X}_{\mathbf{S 2}}$ as illustrated in Fig. 5, and $\mathbf{R}$ and $\mathbf{t}$ be the rotation and the translation between the two sensors. The coplanarity constraint of the points $\mathbf{X}, \mathbf{X}_{\mathbf{S} 1}, \mathbf{X}_{\mathbf{S} 2}, \mathbf{C}_{\mathbf{1}}$ and $\mathbf{C}_{\mathbf{2}}$ can be expressed as follows:

$$
\mathbf{X}_{\mathrm{S} 2} \mathbf{R}\left(\mathbf{t} \times \mathbf{X}_{\mathrm{S} 1}\right)=0
$$

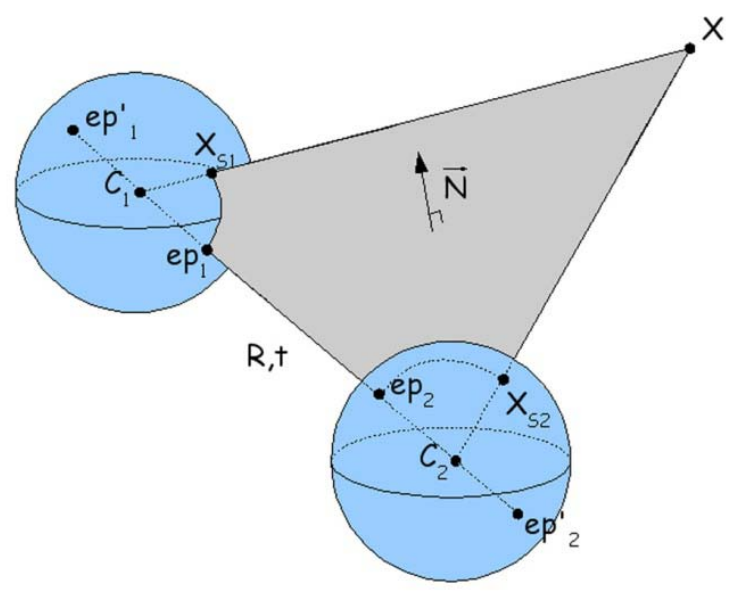

Fig. 5. Epipolar geometry of spherical sensors.

The coplanarity constraint (4) can be expressed in matrix form:

$$
\mathbf{X}_{\mathrm{S} 2}{ }^{T} \cdot \mathbf{E} \cdot \mathbf{X}_{\mathbf{S} 1}=0
$$


where:

$$
\mathbf{E}=\mathbf{R} \cdot \mathbf{S}
$$

is the essential matrix first introduced by Longuet-Higgins [14] and $\mathbf{S}$ is an anti-symmetric matrix characterizing the translation:

$$
\mathbf{S}=\left[\begin{array}{ccc}
0 & -t_{z} & t_{y} \\
t_{z} & 0 & -t_{x} \\
-t_{y} & t_{x} & 0
\end{array}\right]
$$

Given two lifted points $\mathbf{X}_{\mathbf{S} 1}=\left[\begin{array}{lll}x_{1} & y_{1} & z_{1}\end{array}\right]^{T}$ and $\mathbf{X}_{\mathbf{S} 2}=\left[\begin{array}{lll}x_{2} & y_{2} & z_{2}\end{array}\right]^{T}$ corresponding to the same 3D point $\mathbf{X},(5)$ becomes for each pair of matched points:

$$
x_{2} x_{1} e_{11}+x_{2} y_{1} e_{12}+x_{2} z_{1} e_{31}+\cdots+z_{2} z_{1} e_{33}=0
$$

where $\mathbf{E}=\left[\begin{array}{lll}e_{11} & e_{12} & e_{13} \\ e_{21} & e_{22} & e_{23} \\ e_{31} & e_{32} & e_{33}\end{array}\right]$

With $n$ matched points ( $n \geq 8)$, we can build a system of equations [13] of the form:

$$
\mathbf{A} \cdot \mathbf{e}=0
$$

where $\mathbf{e}=\left[\begin{array}{lllllll}e_{11} & e_{12} & e_{13} & \cdots & e_{31} & e_{32} & e_{33}\end{array}\right]^{T}$.

The essential matrix is computed through the following steps:

- Detection of Harris corners,

- Matching of the corners with backward correlation in order to reject the false matches as described in [15],

- Resolution of (9) by Singular Value Decomposition of A.

\subsection{Calibration with Pattern}

To plan its path, a robot must have a metric model of its environment, which implies knowledge of the baseline. Nevertheless, the essential matrix is estimated up to a scale factor with the eight-point algorithm [13], which leads only to a projective reconstruction. To solve this problem, we developed another method for the relative pose estimation problem.

This method uses patterns shown at different positions as with calibration. Let $\mathbf{X}$ be a point with coordinates $\mathbf{X}_{1}=\left[\begin{array}{lll}x_{1} & y_{1} & z_{1}\end{array}\right]^{T}$ in the first frame associated with the first sensor as depicted in Fig. 6 . Its coordinates in the second sensor reference frame can be expressed by:

$$
\left[\begin{array}{l}
x_{2} \\
y_{2} \\
z_{2}
\end{array}\right]=\left[\begin{array}{lll}
r_{11} & r_{12} & r_{13} \\
r_{21} & r_{22} & r_{23} \\
r_{31} & r_{32} & r_{33}
\end{array}\right] \cdot\left[\begin{array}{l}
x_{1} \\
y_{1} \\
z_{1}
\end{array}\right]+\left[\begin{array}{l}
t_{x} \\
t_{y} \\
t_{z}
\end{array}\right]
$$




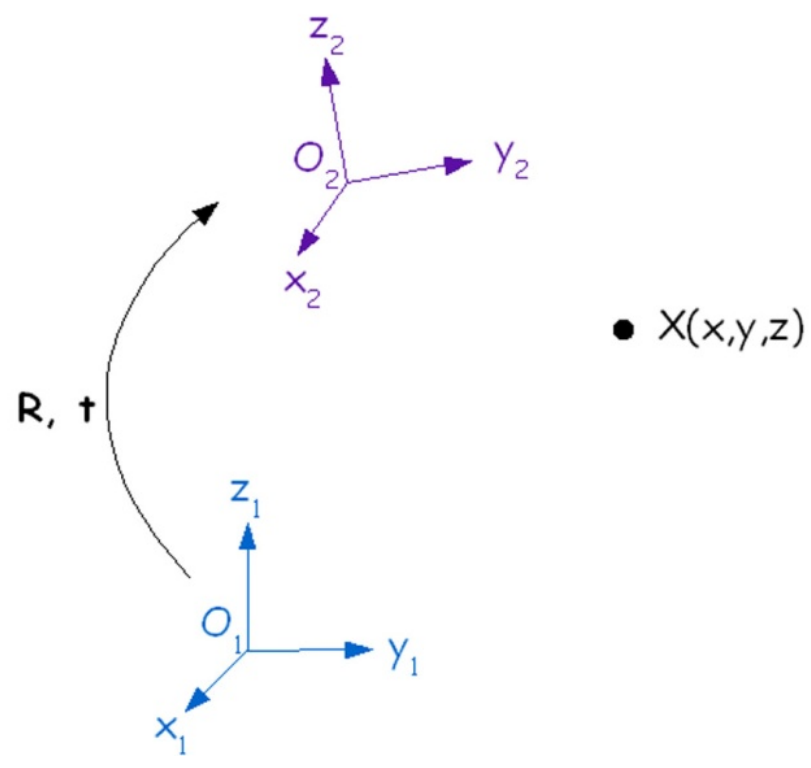

Fig. 6. Relative pose estimation principle.

With $n$ control points, we can build the following system using (10):

$$
\left[\begin{array}{cccccccccccc}
x_{1}^{1} & y_{1}^{1} & z_{1}^{1} & 0 & 0 & 0 & 0 & 0 & 0 & 1 & 0 & 0 \\
0 & 0 & 0 & x_{1}^{1} & y_{1}^{1} & z_{1}^{1} & 0 & 0 & 0 & 0 & 1 & 0 \\
0 & 0 & 0 & 0 & 0 & 0 & x_{1}^{1} & y_{1}^{1} & z_{1}^{1} & 0 & 0 & 1 \\
\vdots & \vdots & \vdots & \vdots & \vdots & \vdots & \vdots & \vdots & \vdots & \vdots & \vdots & \vdots \\
x_{1}^{n} & y_{1}^{n} & z_{1}^{n} & 0 & 0 & 0 & 0 & 0 & 0 & 1 & 0 & 0 \\
0 & 0 & 0 & x_{1}^{n} & y_{1}^{n} & z_{1}^{n} & 0 & 0 & 0 & 0 & 1 & 0 \\
0 & 0 & 0 & 0 & 0 & 0 & x_{1}^{n} & y_{1}^{n} & z_{1}^{n} & 0 & 0 & 1
\end{array}\right] \cdot\left[\begin{array}{c}
r_{11} \\
r_{12} \\
r_{13} \\
r_{21} \\
r_{22} \\
r_{23} \\
r_{31} \\
r_{32} \\
r_{33} \\
t_{x} \\
t_{y} \\
t_{z}
\end{array}\right]=\left[\begin{array}{c}
x_{2}^{1} \\
y_{2}^{1} \\
z_{2}^{1} \\
\vdots \\
x_{2}^{n} \\
y_{2}^{n} \\
z_{2}^{n}
\end{array}\right]
$$

The 3D coordinates of the pattern corners are estimated using the Levenberg-Marquardt algorithm. The resolution of (11) gives the relative pose $(\mathbf{R}, \mathbf{t})$ of the two sensors including the scale factor.

Once the relative pose is computed, the essential matrix can be easily computed using (6).

\section{3D Reconstruction}

The reconstruction consists in determining the $3 \mathrm{D}$ coordinates of a point $\mathbf{X}$, given its projections $\mathbf{x}_{1}$ and $\mathbf{x}_{2}$ onto the two images. Consequently, the first step is to match pixels. 


\subsection{Epipolar Geometry Helps Pixel Matching}

In addition to the essential matrix estimation, epipolar geometry possesses some helpful properties for pixel matching.

For each point $\mathbf{X}_{\mathrm{S} 1}$ on the first unit sphere, the epipolar curve is characterized by the normal of the plane $\mathbf{n}_{2}=\mathbf{E} \cdot \mathbf{X}_{\mathbf{S} 1}$. The epipolar curve on the second image is obtained by determining the intersection of the plane and the second equivalence sphere, which is a great circle. In the same way, $\mathbf{n}_{\mathbf{1}}=\mathbf{E}^{T} \cdot \mathbf{X}_{\mathbf{S 2}}$ characterizes the epipolar curve corresponding to $\mathbf{X}_{\mathrm{S} 2}$ on the second sphere.

The epipoles are the points of intersection of the line joining the centers with the unit sphere. All the epipolar curves intersect at the two epipoles. They can be directly computed from the essential matrix by singular value decomposition as in the classical case [13].

\subsection{Mid-point Method}

In theory, the rays corresponding to two matched pixels must intersect at $\mathbf{X}$. In practice, however, various types of noise (distortions, small errors in the model parameters, etc) lead to lines generated by corresponding image points which do not always intersect. The problem is to find a 3D point which optimally fits the measured image points [13].

This step is achieved by using the mid-point method illustrated in Fig. 7. Lifted points $\mathbf{X}_{\mathbf{S} \mathbf{1}}$ and $\mathbf{X}_{\mathbf{S 2}}$ corresponding to the pixels are first computed using (2). These points are then used to define the direction vectors $\mathbf{v}_{\mathbf{1}}$ and $\mathbf{v}_{\mathbf{2}}$ of the two rays. The $3 \mathrm{D}$ point $\mathbf{X}$ is chosen as the mid-point of the shortest transversal between the two rays.

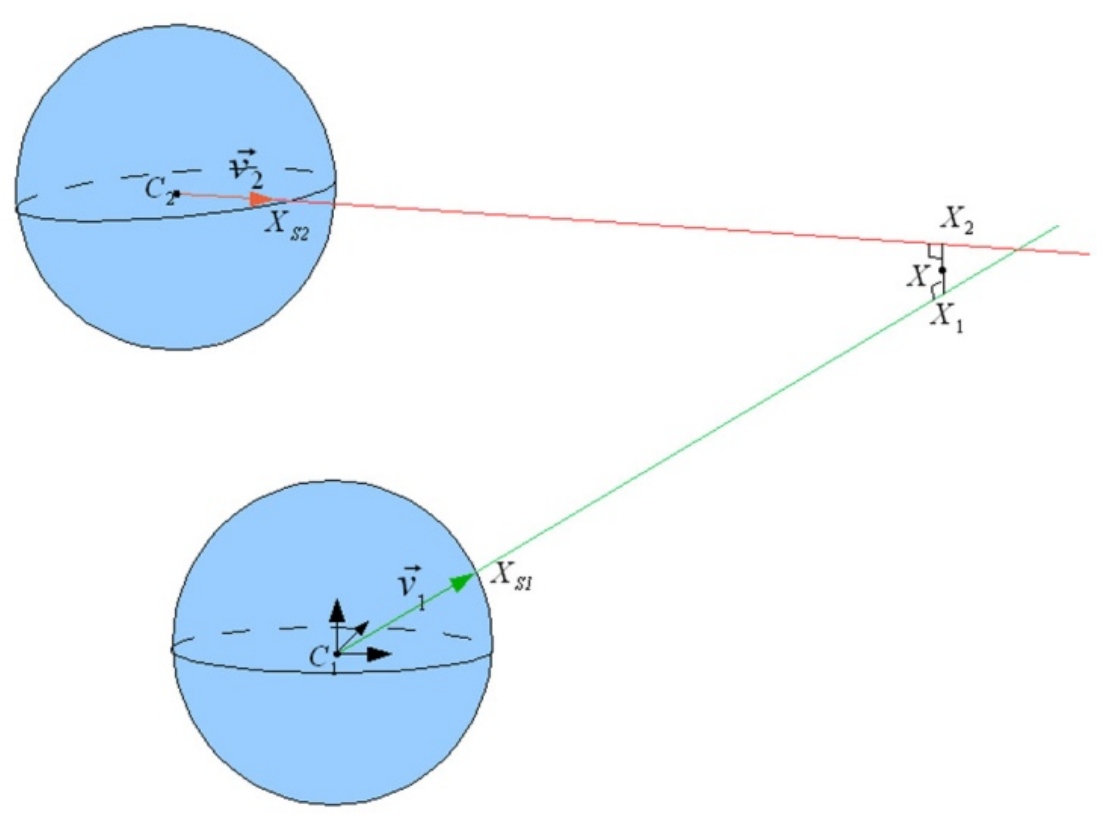

Fig. 7. Mid-point method: the $3 \mathrm{D}$ point $\mathbf{X}$ is chosen as the mid-point of the shortest transversal between the two rays. 


\section{Experimental Results}

Each step of the 3D reconstruction was evaluated and a global result is shown at the end of this section. Experiments were implemented on real images and without prior knowledge to evaluate our system in real conditions.

\subsection{Calibration}

The calibration step was evaluated by computing the Root of Mean Squares (RMS) distances (in pixels) between estimated and theoretical projections of a set of 3D points. As it is very difficult to know precisely the coordinates of a $3 \mathrm{D}$ point in the sensor frame, we used synthetic images.

The sensor was simulated in POV-Ray, a ray-tracing software, to generate omnidirectional images containing a calibration pattern as shown in Fig. 8 and these images were used to calibrate the sensor.

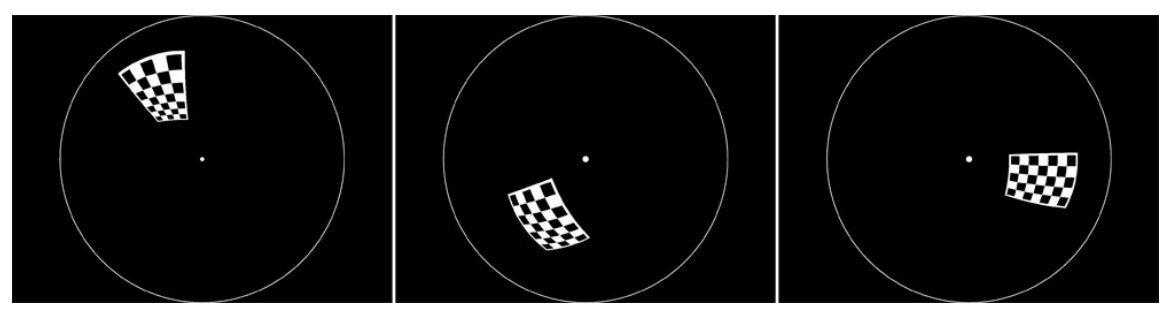

Fig. 8. Synthetic omnidirectional images used for the calibration.

As the projection model and the 3D coordinates of reference points are perfectly known in this case, their theoretical projection can easily be computed [16]. Table 1 shows the mean error and the standard deviation obtained on a set of 150 points.

Table 1. Calibration results on synthetic images.

\begin{tabular}{|l|l|}
\hline Mean error (pixels) & 0.24 \\
\hline Standard deviation (pixels) & 0.11 \\
\hline
\end{tabular}

The calibration was then evaluated on real images. Two sets of omnidirectional images were taken. We used the first set to calibrate the sensor as described in section 4. The second set was used to compute the error between estimated projections of the grids points and their measured projections extracted from the images. Table 2 summarizes the results obtained on this set of real images.

Table 2. Calibration results on real images.

\begin{tabular}{|l|l|}
\hline Mean error (pixels) & 0.44 \\
\hline Standard deviation (pixels) & 0.26 \\
\hline
\end{tabular}

The model parameters obtained by the calibration allows the lifting, i.e. the projection of the pixels onto the unit sphere as shown in Fig. 9. 


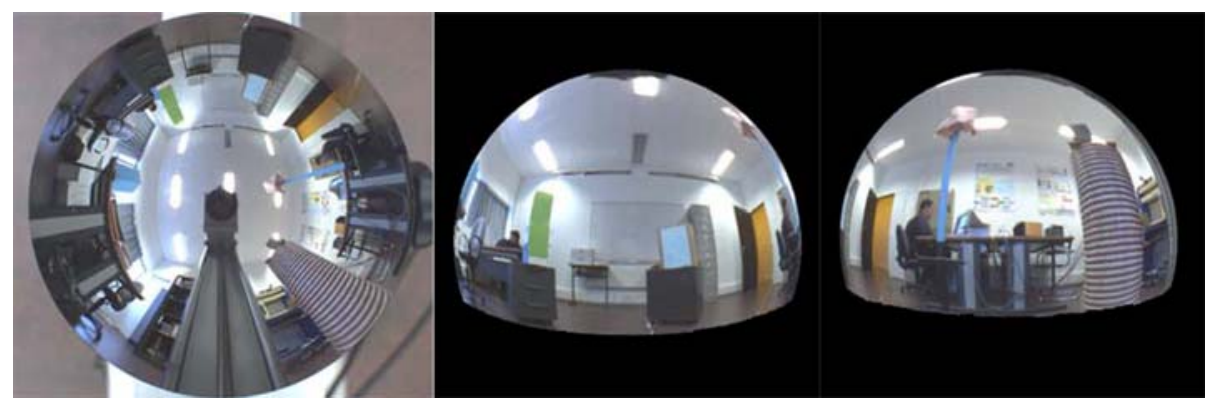

Fig. 9. An omnidirectional image and two views of its projection onto the unit sphere.

\subsection{Relative Pose Estimation}

The relative pose estimation was evaluated on real images. The sensor was mounted on a graduated rail and was moved $10 \mathrm{~cm}$ by $10 \mathrm{~cm}$. At each position, an omnidirectional image was acquired with the aim of computing the displacement of the sensor according to the first position using five calibration patterns placed in the room as shown in Fig. 10. Table 3 summarizes the results. The average error is less than $0.9 \%$.

Table 3. Estimation of the displacements.

\begin{tabular}{|l|l|l|l|l|l|l|}
\hline Displacement (mm) & 100 & 200 & 300 & 400 & 500 & 600 \\
\hline Estimation (mm) & 100.13 & 200.77 & 296.48 & 393.66 & 494.70 & 594.60 \\
\hline
\end{tabular}

Once the relative pose is estimated, we can compute the essential matrix and use it to check epipolar geometry properties. In Fig. 10, for each selected pixel on the left image (red crosses), the corresponding epipolar curve (green curves) is drawn on the right image and vice versa.

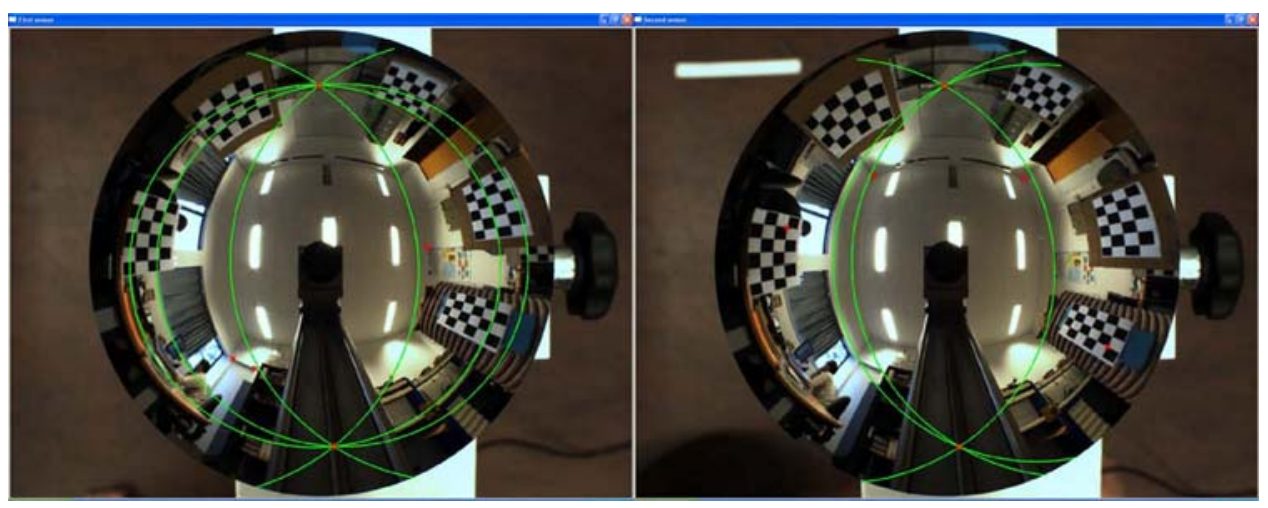

Fig. 10. Epipolar curves (green) corresponding to selected pixels (red crosses).

\subsection{D reconstruction}

We have evaluated our 3D reconstruction method by estimating position of 3D points of five grids disposed on three walls of a room. Images used for this step are presented in Fig. 11. 

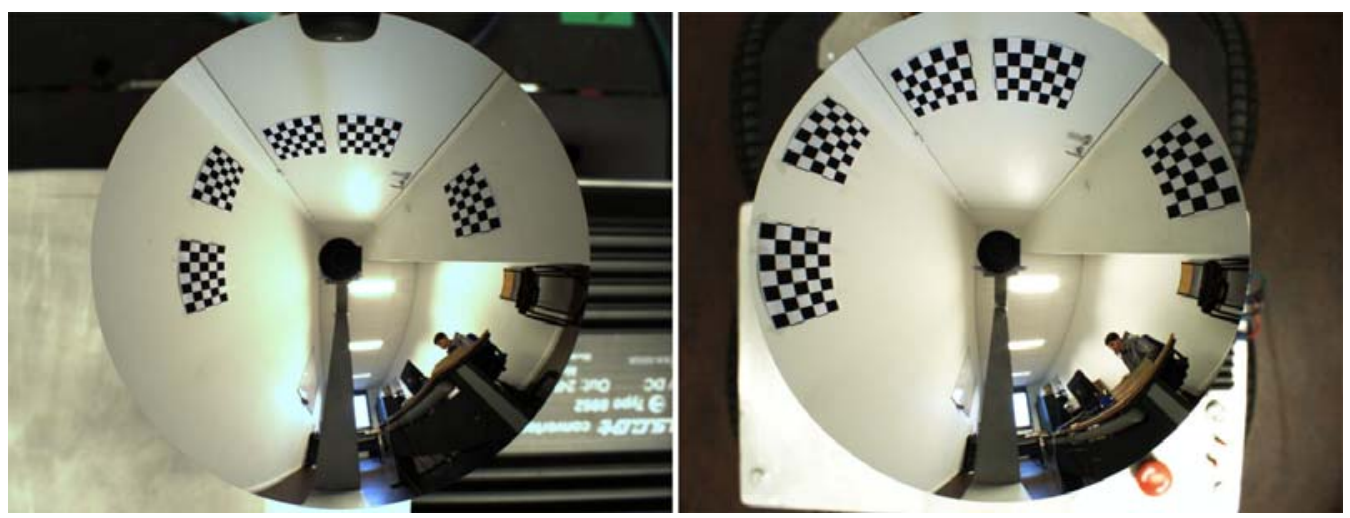

Fig. 11. Stereo pair used for the 3D reconstruction experimentation.

For each grid, the four corners were selected manually on the two images and an automatic corners detector was then used to extract all grid points. The 3D position of these points was evaluated by triangulation and is displayed in Fig. 12. The position of the points is compared to the ground truth obtained by laser telemetry. A linear regression was performed on raw laser data (in blue) to obtain the position of the walls (red lines).

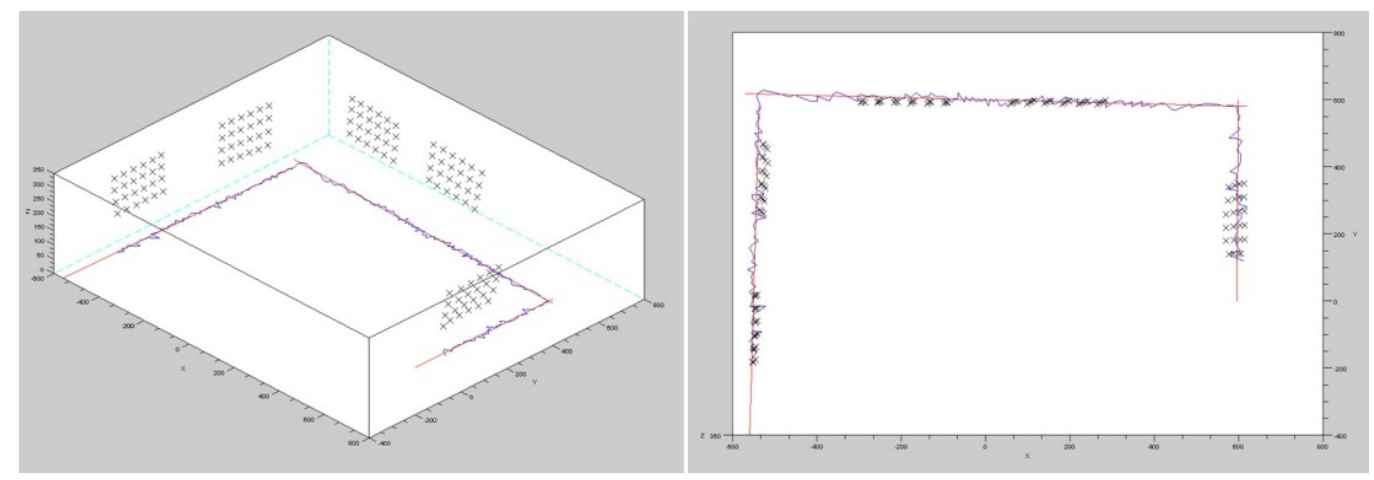

Fig. 12. Position of the five grids (crosses) compared to ground truth (blue and red lines).

For each grid, the mean error and the standard deviation of the position of its points were computed and are summarized in Table 4.

Table 4. Position of the points.

\begin{tabular}{|l|c|c|c|c|c|}
\hline Grid number & 1 & 2 & 3 & 4 & 5 \\
\hline Mean error (mm) & 5.843 & 15.529 & 13.182 & 3.794 & 12.872 \\
\hline Standard deviation (mm) & 2.616 & 4.50 & 2.420 & 2.504 & 7.485 \\
\hline
\end{tabular}

The process was then evaluated by a piecewise planar 3D reconstruction of our laboratory as illustrated in Fig. 13. The four corners of the ceiling were manually selected to check the size of the room. After triangulation, we estimated the ceiling dimension at $6.39 \times 6.34$ meters and the actual size is $6.4 \times 6.4 \mathrm{~m}$. 


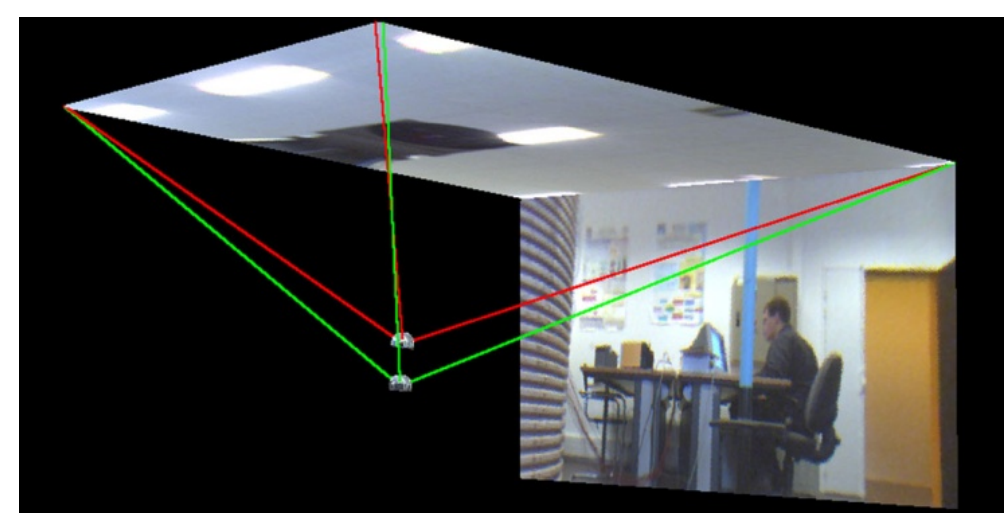

Fig. 13. Piecewise planar 3D reconstruction of our laboratory.

\section{Discussion}

In this paper, we have used a stereovision system based on two catadioptric sensors mounted coaxially one above the other as shown in Fig. 1. Indeed, such a configuration greatly simplifies the epipolar geometry since epipolar curves become radial lines. In this way, matching horizontal lines is simplified while a motion allows vertical lines to be matched. A stereoscopic system also presents advantages compared to a structure from motion method because the baseline is well-known and not estimated by odometry which introduces many errors.

We have chosen to work with a unified model which is valid for all central sensors hence we have to respect the Single-Viewpoint constraint. Our method, presented in section 2, allows us to be as close as possible to the single viewpoint. The choice of the Mei's unified model leads to a very flexible calibration step because the number of parameters to be estimated is quite reasonable and easy to be initialized. A calibration tool was developed in $\mathrm{C}++$ using the computer vision library OpenCV and can be freely downloaded from our website [17]. The calibration tool does not require any commercial software and optimizes the computing time. A calibration with 10 images does not exceed 2 minutes.

Two methods have been developed for the relative pose estimation and have different fields of use. The first one relies on the eight-point algorithm and can be used in line because the process is entirely automatic but gives only the relative pose up to a scale factor. The other one uses calibration patterns and is more adapted for measurement thanks to the entire knowledge of the relative pose. Table 5 summarizes the main characteristics of the two methods used for the relative pose estimation and their field of use. The evaluation of our method using calibration patterns was done by estimating the motion of the sensor. The average error between estimation and real displacements is small (less than $2 \%$ ) and probably induced by image noise which disturbs the corner extraction process. The precision is sufficient for applications such as navigation.

It should be noted that the $3 \mathrm{D}$ reconstruction error presented in Table 4 is very low (around $1 \%$ at 1 meter). Due to the resolution of catadioptric sensors, this error will nevertheless increase with the distance and will be around $10 \%$ at 10 meters. The depth resolution of our system was evaluated in a vertical cross section and is illustrated in Fig. 14. Each point represents the estimated position calculated for every possible pair of image correspondences in a single image radius (an epipolar line due to our sensor configuration). The depth resolution mainly depends on the camera resolution and on the length of baseline. 
Table 5. Comparison between the two relative pose estimation methods.

\begin{tabular}{|l|l|l|}
\cline { 2 - 3 } \multicolumn{1}{c|}{} & \multicolumn{1}{c|}{ Eight-point algorithm } & \multicolumn{1}{c|}{ Estimation with pattern } \\
\hline Input data & a pair of omnidirectional images & $\begin{array}{l}\text { pairs of omnidirectional images with a } \\
\text { calibration pattern }\end{array}$ \\
\hline Hypothesis on data & n points correctly matched & $\begin{array}{l}\text { pattern properties known (size and } \\
\text { number of squares), model parameters }\end{array}$ \\
\hline Output data & $\begin{array}{l}\text { essential matrix which can be } \\
\text { decomposed into relative pose up to a } \\
\text { scale factor }\end{array}$ & $\begin{array}{l}\text { relative pose, the essential matrix can be } \\
\text { easily computed from it }\end{array}$ \\
\hline Error source & false matching & pattern position estimation \\
\hline Computing time & long because of the pixels matching & short \\
\hline Manipulation time & short (automatic process) & $\begin{array}{l}\text { long (manual selection of the four } \\
\text { corners of the pattern) }\end{array}$ \\
\hline Field of use & in line calibration & off line calibration \\
\hline
\end{tabular}

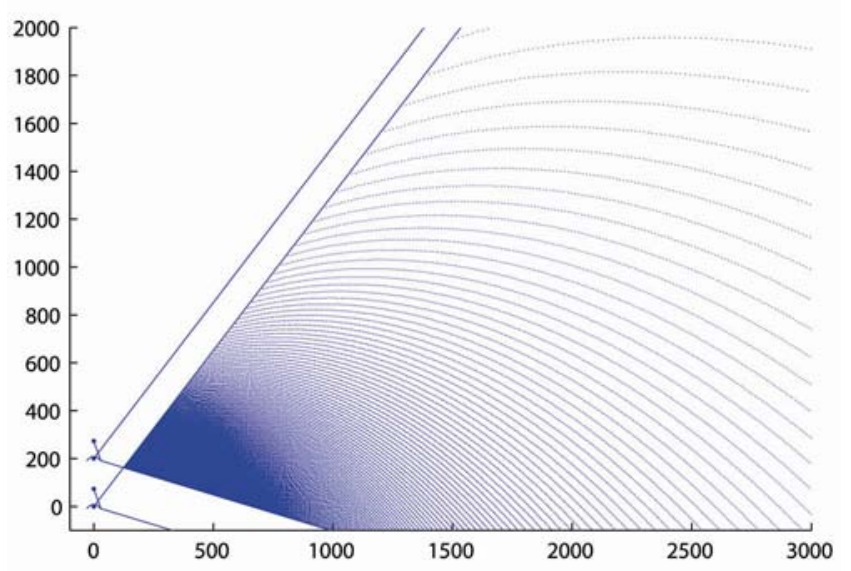

Fig. 14. Depth resolution (in $\mathrm{mm}$ ) for our catadioptric stereovision sensor: the baseline is $200 \mathrm{~mm}$ and the radius is composed of 480 pixels.

The 3D reconstruction results are the outcome of all our methodology: design of the sensor, calibration, relative pose estimation of the two sensors and triangulation. Consequently, the good results obtained imply of reliable estimation of all the parameters.

\section{Conclusion}

In this paper, we have presented a scheme for $3 \mathrm{D}$ reconstruction of the environment of a mobile robot based on a catadioptric stereovision sensor. This scheme can be decomposed into three stages: calibration, estimation of the relative pose of the two sensors and triangulation.

Thanks to an accurate calibration and relative pose estimation, the metric of the scene is well respected and evaluated using real images.

Our future work will focus on automatic reconstruction, using pixel matching or more elaborated primitives (lines, planes, etc). Once 3D reconstruction is achieved, the motion estimation of the robot will be addressed to be able to merge several local reconstructions. 


\section{Acknowledgements}

This research is supported by the DGA (Délégation Générale pour l'Armement), IPSIS (Ingénierie pour Signaux et Systèmes) and IRSEEM (Institut de Recherche en Systèmes Electroniques Embarqués).

\section{References}

[1]. R. Benosman, J. Devars, Panoramic stereovision sensor, in Proceedings of the International Conference on Pattern Recognition (ICPR'1998), 1998, pp. 767-769.

[2]. S. Baker, S. Nayar, A theory of single-viewpoint catadioptric image formation, International Journal of Computer Vision, 35, 2, 1999, pp. 175-196.

[3]. E. Mouaddib, Introduction à la vision panoramique catadioptrique, Traitement du Signal, 22, 5, 2005, pp. 409-417 (In French).

[4]. J. Bouguet, http://www.vision.caltech.edu/bouguetj/

[5]. S. Ramalingram, P. Sturm, S. Lodha, Towards complete generic camera calibration, In Proceedings of the International Conference on Computer Vision and Pattern Recognition (CVPR'2005), 2005, pp. 1093-1098.

[6]. N. Ragot, J. Ertaud, X. Savatier, B. Mazari, Calibration of a panoramic stereovision sensor: Analytical vs interpolation-based methods, in Proceedings of the Industrial Electronics Conference (IECON'2006), 2006, pp. 4130-4135.

[7]. J. Gonzalez-Barbosa, S. Lacroix, Fast dense panoramic stereovision, in Proceedings of the International Conference on Robotics and Automation (ICRA'2005), 2005, pp. 1210-1215.

[8]. C. Mei, P. Rives, Single view point omnidirectional camera calibration from planar grids, in Proceedings of the International Conference on Robotics and Automation (ICRA'2007), 2007, pp. 3945-3950.

[9]. D. Scaramuzza, A. Martinelli, R. Siegwart, A flexible technique for accurate omnidirectional camera calibration and structure from motion, in Proceedings of the International Conference on Computer Vision Systems (ICVS'2006), 2006, pp. 45-52.

[10].C. Geyer, K. Daniilidis, A unifying theory for central panoramic systems and practical implications, In Proceedings of the European Conference on Computer Vision (ICCV'2000), 2000, pp. 445-461.

[11].J.P. Barreto, A unifying geometric representation for central projection systems, Computer Vision and Image Understanding, 103, 3, 2006, pp. 208-217.

[12].Z. Zhang, Determining the epipolar geometry and its uncertainty: A review, International Journal of Computer Vision, 27, 2, 1998, pp. 161-195.

[13].R. Hartley, A. Zisserman, Multiple View Geometry in Computer Vision, Second Edition, Cambridge University Press, 2004.

[14].H. Longuet-Higgins, A computer algorithm for reconstructing a scene from two projections, Nature, 293, 1981, pp. 133-135.

[15].P. Werth, S. Scherer, A novel bidirectional framework for control and refinement of area based correlation techniques, In Proceedings of the International Conference on Pattern Recognition (ICPR'2000), 2000, pp. 730-733.

[16].J. Gonzalez-Barbosa, Vision panoramique pour la robotique mobile: stereovision et localization par indexation d'images, Ph.D. Thesis, Toulouse III, 2004 (In French).

[17].R. Boutteau, 3D reconstruction for autonomous navigation (http://omni3d.esigelec.fr/ doku.php/thesis/r3d/start).

2009 Copyright $\mathbb{0}$, International Frequency Sensor Association (IFSA). All rights reserved.

(http://www.sensorsportal.com) 


\title{
Guide for Contributors
}

\begin{abstract}
Aims and Scope
Sensors \& Transducers Journal (ISSN 1726-5479) provides an advanced forum for the science and technology of physical, chemical sensors and biosensors. It publishes state-of-the-art reviews, regular research and application specific papers, short notes, letters to Editor and sensors related books reviews as well as academic, practical and commercial information of interest to its readership. Because it is an open access, peer review international journal, papers rapidly published in Sensors \& Transducers Journal will receive a very high publicity. The journal is published monthly as twelve issues per annual by International Frequency Association (IFSA). In additional, some special sponsored and conference issues published annually.
\end{abstract}

\section{Topics Covered}

Contributions are invited on all aspects of research, development and application of the science and technology of sensors, transducers and sensor instrumentations. Topics include, but are not restricted to:

- Physical, chemical and biosensors;

- Digital, frequency, period, duty-cycle, time interval, PWM, pulse number output sensors and transducers;

- Theory, principles, effects, design, standardization and modeling;

- Smart sensors and systems;

- Sensor instrumentation;

- Virtual instruments;

- Sensors interfaces, buses and networks;

- Signal processing;

- Frequency (period, duty-cycle)-to-digital converters, ADC;

- Technologies and materials;

- Nanosensors;

- Microsystems;

- Applications.

\section{Submission of papers}

Articles should be written in English. Authors are invited to submit by e-mail editor@sensorsportal.com 6-14 pages article (including abstract, illustrations (color or grayscale), photos and references) in both: MS Word (doc) and Acrobat (pdf) formats. Detailed preparation instructions, paper example and template of manuscript are available from the journal's webpage: http://www.sensorsportal.com/HTML/DIGEST/Submition.htm Authors must follow the instructions strictly when submitting their manuscripts.

\section{Advertising Information}

Advertising orders and enquires may be sent to sales@sensorsportal.com Please download also our media kit: http://www.sensorsportal.com/DOWNLOADS/Media_Kit_2008.pdf 

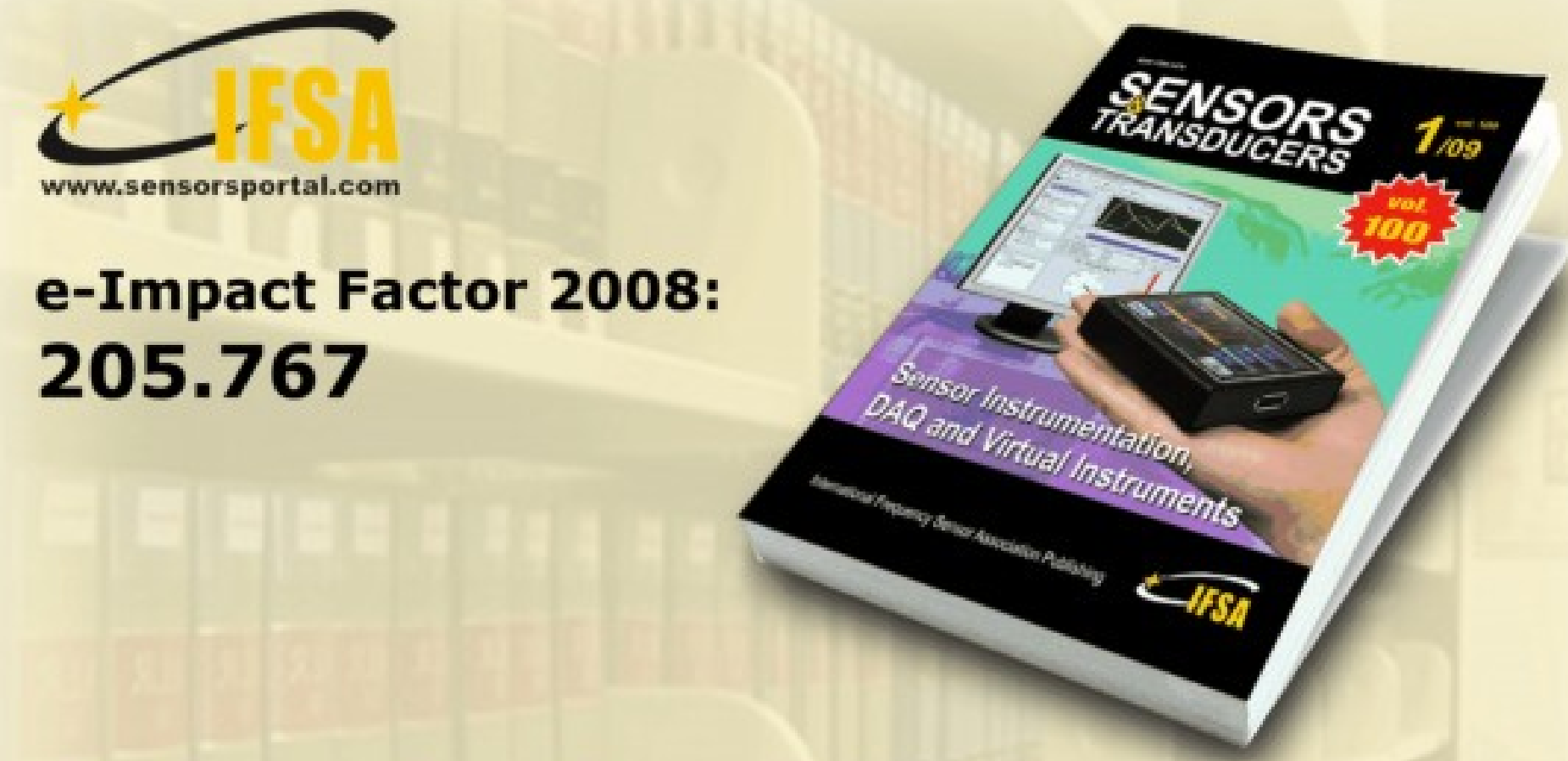

\section{Subscription 2009}

Sensors \& Transducers Journal (ISSN 1726-5479) for scientists and engineers who need to be at cutting-edge of sensor and measuring technologies and their applications.

Keep up-to-date with the latest, most significant advances in all areas of sensors and transducers.

\section{Take an advantage of IFSA membership and save $40 \%$ of subscription cost.}

Subscribe online:

http://www.sensorsportal.com/HTML/DIGEST/Journal_Subscription_2009.htm e-mail: editor@sensorsportal.com tel. +34696067716

\section{www.sensorsportal.com}

